\title{
COLLEGIATE RECOVERY PROGRAMS AND TREATMENT PROVIDERS: SUPPORTING OUTCOMES, NOT ADMISSIONS SIERRA CASTEDO*, NICO DOORN
}

*SCASTEDO@AUSTIN.UTEXAS.EDU; THE CENTER FOR STUDENTS IN RECOVERY AT THE UNIVERSITY OF TEXAS AT AUSTIN, 2109 SAN JACINTO BLVD, E8000 BEL 222, AUSTIN, TX 78712

To cite this article: Castedo, S. \& Doorn, N. (2018). Collegiate Recovery Programs and Treatment Providers: Supporting Outcomes, Not Admissions. Journal of Recovery Science, 1(2), c9. https://doi.org/10.31886/jors.12.2018.26

To link to this article: https://doi.org/10.31886/jors.12.2018.26

\section{ABSTRACT}

Collegiate Recovery Programs (CRPs), rooted in slow-moving academic institutions, can be contrasted with relatively fast-moving private treatment entities, and this contrast has great potential for both conflict and mutual benefit. Conflict may arise from a misunderstanding about the role of CRPs in the continuum of care - frequently thought to be a referral source, when, in fact, they work best as a post-treatment resource, improving outcomes for students in recovery. Young adults are the fastest growing demographic seeking treatment for substance use disorders, and, because of this changing age profile, more treatment entities are seeking to serve young adults and coming into contact with CRPs. This presentation explores the nuances and ethical challenges facing those interactions and describes the benefits of collaboration when pursued thoughtfully. The experiences of a CRP and a sober living/IOP facility in Austin, Texas will also be presented as a framework for collaboration.

\section{COMMUNITY COLLEGES: THE NEXT FRONTIER OF RECOVERY SUPPORT AT INSTITUTIONS OF HIGHER EDUCATION}

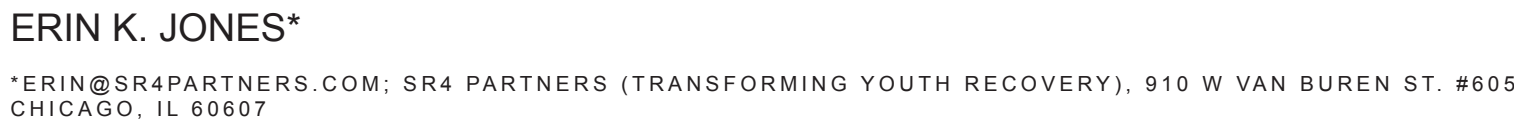

To cite this article: Jones, E. K. (2018). Community Colleges: The Next Frontier of Recovery Support at Institutions of Higher Education. Journal of Recovery Science, 1(2), c9. https://doi.org/10.31886/jors.12.2018.27

To link to this article: https://doi.org/10.31886/jors.12.2018.27

\section{ABSTRACT}

In 2016, TYR could identify only six community colleges offering recovery support programs and services. Based on this finding, TYR identified a need for pilot programs to better understand programmatic models that may be effective for supporting students in recovery at community colleges. TYR's Bridging the Gap grant program supports these pilot programs and is intended to act as a catalyst for building capacity for recovery support on community college campuses across the U.S. The goal of the program is two-fold; first, to help more 2-year institutions initiate recovery support programs and services and second, to study what programs and services are viewed as helpful and useful to students in recovery so that best practices can be shared as the field develops. This session provided a recap of TYR's 2016 research, observations from Year 1 of the grant program, and a discussion on survey responses on institutional attitudes and student engagement in recovery support on 2-year campuses.

All authors approve this manuscript and the original submission. The authors report no conflicts of interest. This work is licensed under the CC-BY license. 